DOI: $10.4274 /$ jarem.galenos.2021.19483

J Acad Res Med 2021;11(3):277-82

\title{
Diagnostic and Prognostic Value of M30 and M65 in Laryngeal Squamous Cell Carcinoma
}

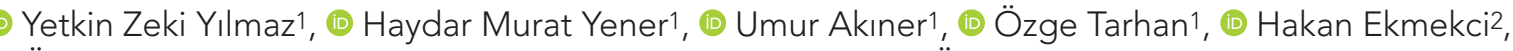
(1) Özlem Balcı Ekmekci2, (1) Mehmet Yılmaz³, (1) Hasan Ahmet Özdoğan

${ }^{1}$ istanbul University-Cerrahpaşa, Cerrahpaşa Faculty of Medicine, Department of Otorhinolaryngology, İstanbul, Turkey ${ }^{2}$ istanbul University-Cerrahpaşa, Cerrahpaşa Faculty of Medicine, Department of Biochemistry, İstanbul, Turkey

${ }^{3}$ Yunus Emre Surgery Clinic, Department of Otorhinolaryngology, İstanbul, Turkey

Cite this article as: Yılmaz YZ, Yener HM, Akıner U, Tarhan Ö, Ekmekci H, Balcı Ekmekci Ö, Yılmaz M, Özdoğan HA. Diagnostic and Prognostic Value of M30 and M65 in Laryngeal Squamous Cell Carcinoma. J Acad Res Med 2021;11(3):277-82

\begin{abstract}
Objective: This study aimed to investigate the preoperative and postoperative plasma M30 and M65 levels in laryngeal squamous cell carcinoma (LSCC) and its relationship with the prognostic value, clinical stage, histological differentiation, and lymph node metastasis.

Methods: This study was prospectively conducted, which included 29 patients with LSCC (group 1) and 19 healthy individuals (group 2). The venous blood was collected from all patients in the preoperative and first postoperative months. Serum M30 and M65 levels were determined by enzymelinked immunosorbent assay.

Results: A statistically significant difference was found in serum M30 levels between groups 1 and 2. (Median: 233.94 U/L vs. 95.17 U/L) ( $p=0.001)$, whereas no significant difference was found in serum M65 values in groups 1 and 2 (median: $350.67 \mathrm{U} / \mathrm{L}$ vs. $309.94 \mathrm{U} / \mathrm{L})(\mathrm{p}<0.387$ ).

Conclusion: The preoperative and postoperative serum M30 and M65 levels in the patients with laryngeal carcinoma were evaluated, which evaluated M30 levels were high not only in advanced-stage tumors but also in early staged tumors. Thus, following the M30 level may be useful for the early diagnosis of laryngeal cancers.
\end{abstract}

Keywords: Keratin-18, M30, M65, apoptosis, laryngeal squamous cell carcinoma 


\section{INTRODUCTION}

Laryngeal squamous cell carcinoma (LSCC) is one of the most common malignancies in males and the second most common malignancy in the head and neck region $(1,2)$. Moreover, $2.4 \%$ of all newly diagnosed malignancies are added to the total number annually $(1,2)$. Early-stage laryngeal cancers have a better prognosis than advanced stage cancers (3). Thus, early detection of laryngeal cancer provides more curative treatment functional and preservative surgery. Late presenting malignancies reduce the treatment efficacy and increase the recurrence rate (4). Therefore, new diagnostic markers for early LSSC detection will be useful and helpful in outcome prediction.

$\mathrm{M} 30$ and M65 are different circulating fragments of cytokeratin-18 (CK-18), which is an important constituent of the intermediate filament system. They are primary insoluble molecules that play a substantial role in cellular mechanisms (cellular manner, motility, division, and cell-cell contact). CK-18 is a cytoskeletal protein that is primarily found in the epithelial cell lining of the respiratory and gastrointestinal tracts and is usually expressed during malignant transformation (5). Necrosis of malignant and normal epithelial cells releases CK-18 $(6,7)$. Caspase-mediated cleavage of the CK18 contributes to the degradation of the intracellular cytoskeleton if epithelial cells undergo apoptosis (8).

After plasma concentrations of both full-length CK-18 (M65) and caspase-cleaved CK-18 fragments (M30) that is measured by enzyme-linked immunosorbent assay (ELISA), the studies on specific tumor types, including the lungs, breast, prostate, head and neck, colorectal, and testicular tumors were initiated (6,9-16). This study was designed to show the diagnostic and prognostic value of M30 and M65 in LSCC.

\section{METHODS}

\section{Patients}

This study was conducted at the Otolaryngology Department of İstanbul University-Cerrahpaşa, Cerrahpaşa Faculty of Medicine and included 29 patients with primary LSCC, of which diagnosis was confirmed by preoperative histological biopsy, as group 1. Additionally, group $2(n=19)$ included participants of similar age, who smoked without any systemic diseases, as the control. Patients with active infection, immunosuppression, and other malignancies were excluded from the study. The study was approved by the İstanbul University-Cerrahpaşa Ethics Committee (approval number: B.30.2.isT.0.30.90.00/19047, date: 16.07.2021). This study was supported by the Scientific Research Projects Coordination Unit of İstanbul University (project number: 25617).

Patients were staged according to the tumor, node, and distant metastasis (TNM) classification of the International Union against cancer (17). Tumor extent, nodal involvement, and distant metastasis of the LSCC were assessed by physical examination, panendoscopy, and imaging studies (positron emission tomography, computed tomography, and magnetic resonance imaging). All patients were surgically treated, either by partial or total laryngectomy with or without neck dissection according to the tumor stage. Postoperative radiotherapy (RT) or chemoradiotherapy (CRT) was planned by postoperative definitive pathologic findings. Informed consent was obtained from all participants.

\section{Samples}

Serum samples were obtained after 12 -h fasting by centrifugation of clotted specimen within 30 minutes to determine the M30 [caspase-cleaved keratin 18 (ccK18 or M30 neo-epitope)] and M65 [soluble keratin 18 (K18)]. The separated serum samples were stored in several small aliquots at $-70^{\circ} \mathrm{C}$ until assayed. In group 1 , the first blood samples were taken before surgery and the second at the first month after surgery, and before the RT and/or CRT.

\section{Laboratory Methods}

ELISA procedure was used to determine the serum M30 and M65 levels (Peviva AB, Bromma, Sweden; Cat No: 10010 and 10020; respectively). The M65 ELISA assay measures total soluble K18 that are released from dead cells (necrotic and apoptotic). Whereas, M30 ELISA assay specifically detects apoptotic death. Combining the two assays may be useful for assessing cell death mode. Our study performed all determinations according to the manufacturer's instructions. The final step of the procedures measured the absorbance in a microplate reader at $450 \mathrm{~nm}$. By plotting a standard curve, the M30 and M65 levels were expressed as $U / L$ from known concentrations versus measured absorbance. The measuring ranges of M30 and M65 kits were 0-1,000 U/L and 0-2,000 U/L, respectively.

\section{Statistical Analysis}

The Statistical Package for the Social Sciences Version 21.0 (SPSS Inc., Chicago, IL., USA) was used for statistical analysis. The normal distribution of data was analyzed with the Kolmogorov-Smirnov test, and Levene's tests were used to assess homogeneity. The Wilcoxon signed-rank test and Mann-Whitney $U$ test were used to compare the groups. The statistically significant level was set as a $\mathrm{p}$-value of $<0.05$.

\section{RESULTS}

Group 1 (study group, n=29) included 3 (10.3\%) female and 26 male $(89.7 \%)$ patients, with a mean age of 58.1 (minimum: 34; maximum: 74) years. Group 2 (control group, $n=19$ ) included 2 female (10.5\%) and 17 (89.5\%) healthy males with a mean age of 57 (minimum: 30; maximum: 70) years.

All patients were treated by surgery, and 3 received adjuvant CRT (10\%), 10 received adjuvant RT (34\%), and 1 received adjuvant CRT. Neck dissection was not performed on 5 patients with early stage glottic carcinoma who were graded as $N_{0}$ according to preoperative assessments.

The difference between preoperative serum M30 levels in groups 1 and 2 were statistically significant $(p<0.05)$ (Table 1, Figure 1$)$. The difference between preoperative serum M65 levels in groups 1 and 2 were not statistically significant $(p>0.05)$ (Table 1). Increased 
postoperative M30 and M65 serum levels were found in group 1 ; however, the comparison of preoperative and postoperative serum M30 and M65 levels was not statistically significant $(p>0.05)$ (Table 1).

The statistical analysis according to nodal status $\left(\mathrm{N}+, \mathrm{N}_{0}\right)$ revealed that preoperative and postoperative serum M30 and M65 levels were not statistically significant $(p>0.05)$. The comparison according to the stage (early, advanced) revealed 13 patients with early and 16 patients with advanced laryngeal carcinoma. When the difference between the preoperative and postoperative serum $\mathrm{M} 30$ and $\mathrm{M} 65$ level in patients with early and advanced stages were not statistically significant $(p>0.05)$. The group analyses according to T-stage $\left(T_{1-2,} T_{3-4}\right)$ revealed that the comparison of preoperative and postoperative $M 30$ and M65 levels in patients with $T_{1-2}(n=20)$ and $T_{3.4}$ tumors $(n=9)$ was not a significantly different $(p>0.05)$ (Table 2).

Table 3 represents preoperative $\mathrm{M} 30$ and $\mathrm{M} 65$ values of $\mathrm{N}_{0^{\prime}} \mathrm{N}+$, $\mathrm{T}_{1-2^{\prime}}, \mathrm{T}_{3-4^{\prime}}$ and advanced and early stages in patients from group 1 , and the data was compared with group 2. The preoperative M30 values in $\mathrm{N}_{0}, \mathrm{~N}+, \mathrm{T}_{1-2^{\prime}} \mathrm{T}_{3-4^{\prime}}$ and early and advanced stages were significantly higher than the control group, whereas the preoperative M65 values did not show any statistically significant difference $(p>0.05)$ (Table 3).

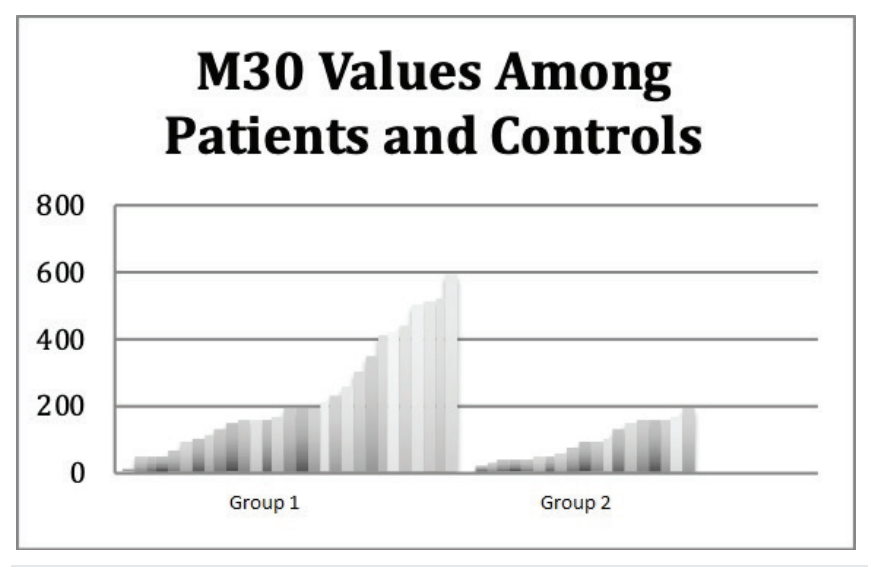

Figure 1. Preoperative serum M30 levels in groups 1 and 2

\section{DISCUSSION}

The survival rate of patients with advanced laryngeal cancer is low according to early-stage laryngeal cancer and is estimated to be 73-92\% for early-stage (stages 1 and 2) laryngeal cancer, conversely $35 \%$ to $64 \%$ for late-stage laryngeal cancer (stages 3 and 4) $(17,8,10)$. Late diagnosis is one of the most important reasons. Mortality and morbidity are increasing by invasion and metastatic potential and high recurrence rate in advanced laryngeal carcinoma. Therefore, some diagnostic tests may be useful for its early diagnosis.

CKs have been attested to play a role in the filtration of tumors into the surrounding tissue. The two forms of CK-18 appear to designate the proportion of apoptosis within the total cell death $(8,18)$. M30 and M65 are considerably new markers that designate different circulating forms of the epithelial cells' structural protein, CK-18. M30 levels remark the caspase-cleavage form of CK-18 in the serum, whereas M65 remarks a broad epitope present in full-length protein, as well as in the caspase-cleaved fragment, thereby identifying CK-18 set free by tissue necrosis in addition to apoptosis (6). They are biomarkers for tumor cell death (18). M65 measures both caspase-cleavage (apoptosis) and cellular release of intact CK-18 during necrosis (18). Additionally, M65 was demonstrated to be a marker of tumor growth in control animals (18), which can be detected both in the plasma and serum of patients. Greystoke et al. (19) reported that M30 and M65 assays were reliable in the serum compared in plasma. Serum M30 and M65 were resistant to processing variation, including delays.

Serum M30 and M65 have been studied in a variety of cancers. Ueno et al. (20) found higher M30 levels in patients with breast cancer compared to healthy subjects. However, any relation between M30 levels and prognosis was not found (20). Dive et al. (21) reported that the median M65 levels in patients with metastatic pancreatic cancer were higher than those with locally advanced or resectable pancreatic cancer. However, M65 levels both in healthy control and patients with pancreatic cancer were not compared (21).

Ulukaya et al. (10) evaluated only M30 levels among patients with non-squamous cell lung cancer (NSCLC) or benign lung disease and healthy group and reported that M30 levels were higher in

Table 1. Preoperative (preop) and postoperative (postop) M30 and M65 values of patients and controls

\begin{tabular}{|l|l|l|l|l|l|}
\hline & $\begin{array}{l}\text { Preop M30, mean } \\
\pm \text { SD, (min-max) } \\
\text { (median) }\end{array}$ & $\begin{array}{l}\text { Postop M30, mean } \\
\pm \text { SD, (min-max) } \\
\text { (median) }\end{array}$ & p-value* & $\begin{array}{l}\text { Preop M65, } \\
\text { mean } \pm \text { SD } \\
\text { (min-max) } \\
\text { (median) }\end{array}$ & $\begin{array}{l}\text { Postop M65 } \\
\text { mean } \pm \text { SD } \\
\text { (min-max) } \\
\text { (median) }\end{array}$ \\
\hline $\begin{array}{l}\text { Group } 1 \\
(n=29)\end{array}$ & $\begin{array}{l}293,93 \pm 165.56 \\
(15,957-513,150)\end{array}$ & $\begin{array}{l}255,93 \pm 157,72 \\
(58,265-582,480)\end{array}$ & 0.627 & $\begin{array}{l}350,67 \pm 143,24 \\
(126,920-668,330)\end{array}$ & $\begin{array}{l}372,64 \pm 224,09 \\
(128,830-993,780)\end{array}$ \\
\hline $\begin{array}{l}\text { Group } 2 \\
(n=19)\end{array}$ & $(193,160)$ & $(193,160)$ & & $(332,09)$ & 0.754 \\
\hline p-values & $(17,038-196,587)$ & $(17,038-196,587)$ & & $309,94 \pm 93)$ & $309,94 \pm 93,52$ \\
\hline
\end{tabular}

*Wilcoxon signed-rank test, ${ }^{* \star M a n n}-$ Whitney $\mathrm{U}$ test, $\mathrm{p}<0.05$, SD: standard deviation, min-max: minimum-maximum 
Table 2. Preoperative and postoperative M30 and M65 values and their comparison in patients who are grouped according to TNM classification

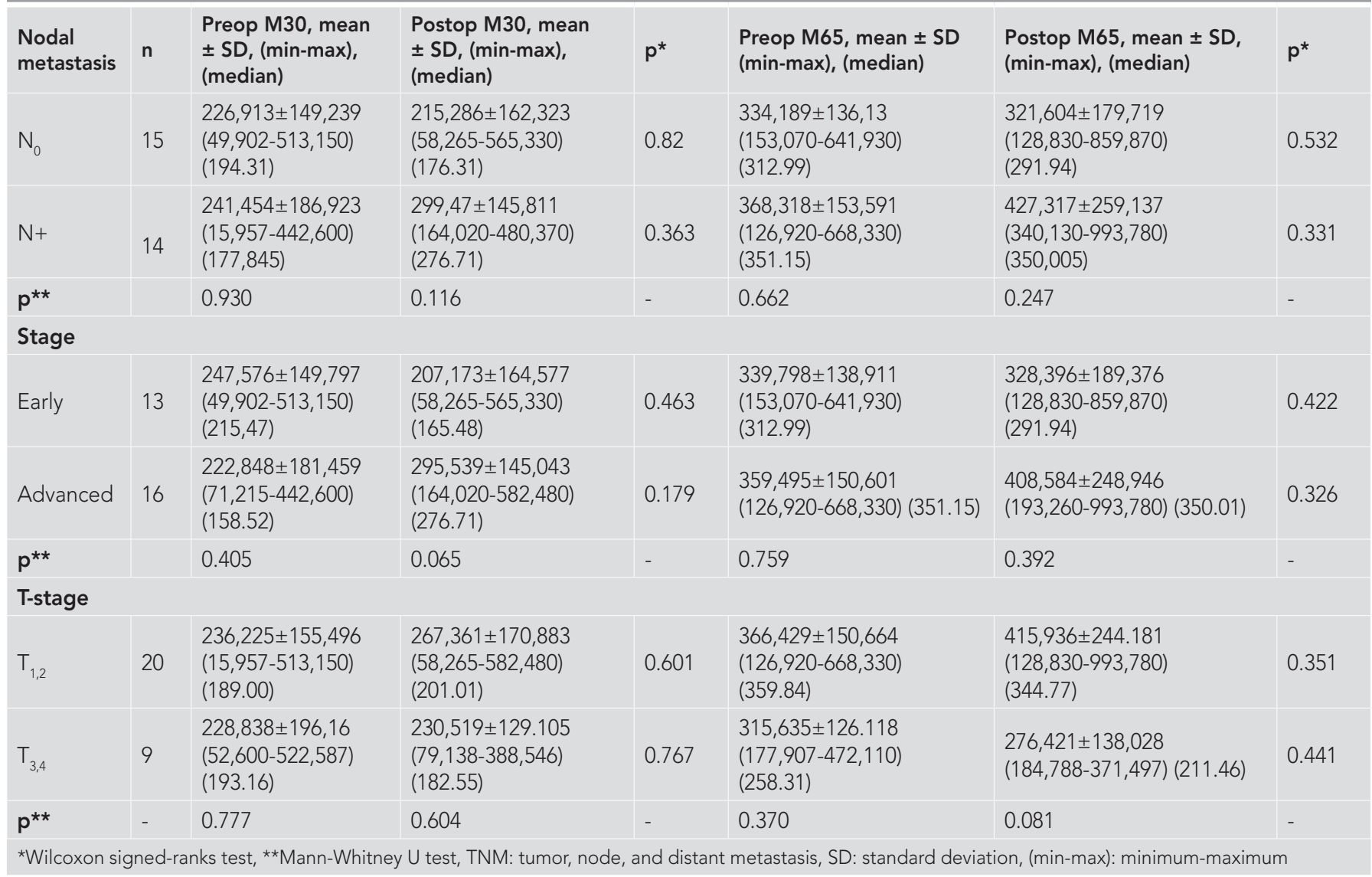

Table 3. Comparison of preoperative M30 and M65 levels in patients and controls according to N status, disease stage, and T-stage

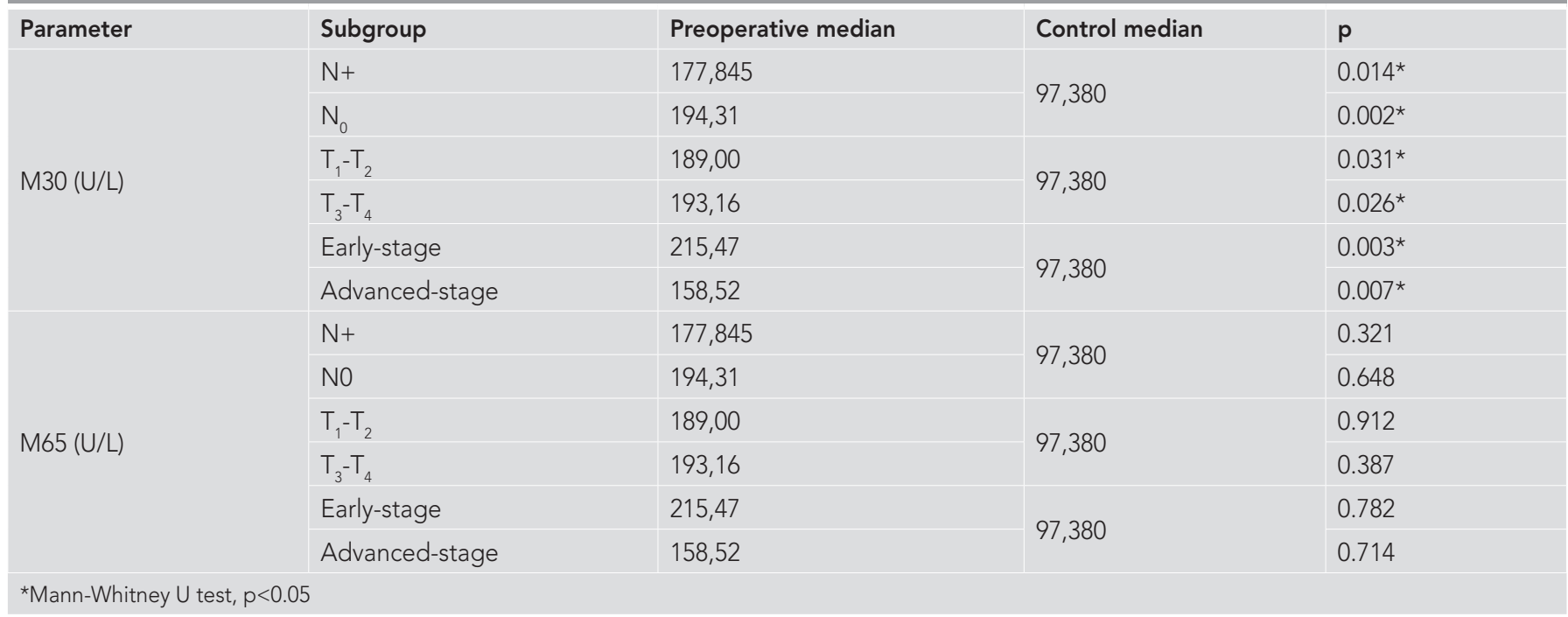

patients with NSCLC. Moreover, they found a relation between poorer survival and increasing M30 levels of patients (10). Hou et al. (11) reported that M30, M65, and circulating tumor cells were higher in patients with small-cell lung cancer. Yaman et al. (22) found that both serum M30 and M65 levels were significantly increased in patients with advanced gastric cancer compared to the control group, and patients with metastatic disease had significantly higher M30 levels compared to patients with locally advanced disease. Bilici et al. (23) reported that plasma M65, but not M30 levels, was significantly increased in patients compared 
to healthy control in advanced gastric cancer. A study performed by de Haas et al. (16) revealed that serum M30 level was an important prognostic factor, such as lactate dehydrogenase, alpha-fetoprotein, and $\beta$-human chorionic gonadotropin, in testicular cancer. Additionally, another study that focused on the urogenital system reported that M30 levels were correlated with the grade, stage, and Ki-67 index of endometrial cancer (24).

The study that was conducted by Ozturk et al. (13) was the first study on M30 and M65 levels in patients with advanced head and neck squamous cell carcinomas (HNSCC), which found a statistical significance between the M30 levels of the patient and control groups. The average serum M65 levels were higher in patients with HNSCC; however, statistical significance was not found. They also revealed no correlation between age, sex, stage, and localization of the tumor and serum M30 and M65 levels. Our study analyzed the availability of serum M30 and M65 concentrations as a diagnostic test and a prognostic marker in patients with laryngeal carcinoma and found that plasma M30 levels in patients with laryngeal cancer were significantly higher than healthy controls, but not M65. Moreover, the comparison of serum M30 levels in early and late-stage laryngeal carcinoma found no statistically significant difference between M30 levels. Thus, the M30 level may be useful for the early diagnosis of laryngeal cancers.

Patients were analyzed according to the T-stage, which revealed no significant difference in M30 and M65 levels in $\mathrm{T}_{1-2}$ and $\mathrm{T}_{3-4}$ tumors. This study included patients with early-stage tumors in addition to advanced-stage laryngeal cancers like previous studies. Therefore, increased M30 levels in both patients with advanced and early stages were one of the important study results. Many studies suggest that cervical lymph node metastasis is the most important prognostic factor for laryngeal cancer $(25,26)$. Jose et al. (27) showed that the 5-year survival rate decreased by approximately $50 \%$ in patients with cervical lymph node metastasis. In this study, the comparison of preoperative and postoperative M30 and M65 levels in patients with or without cervical lymph node metastasis revealed no significant difference.

\section{Study Limitations}

The limitation of this study is the small number of participants.

\section{CONCLUSION}

The preoperative and postoperative serum M30 and M65 levels in the patients with laryngeal carcinoma were evaluated. Serum M30 levels in patients with LSCC were higher compared to healthy subjects. Moreover, M30 levels were high, not only in advancedstaged tumors but also in early-stage tumors that were not previously studied. Therefore, M30 could serve as a promising biomarker candidate in LSCC. The levels of M30 and M65 were not significantly different in patients with nodal metastasis or advanced tumor stage, which may indicate that M30 and M65 cannot be used as prognostic markers in laryngeal carcinoma. Future prospective studies are needed to evaluate the prognostic importance of these markers on laryngeal cancer.
Ethics Committee Approval: The study was approved by the İstanbul University-Cerrahpaşa Ethics Committee (approval number: B.30.2.isT.0.30.90.00/19047, date: 16.07.2021).

Informed Consent: Informed consent was obtained from all participants.

Peer-review: Externally and internally peer-reviewed.

Author Contributions: Concept - M.Y., H.A.Ö.; Design - Y.Z.Y., H.M.Y., M.Y.; Data Collection and/or Processing - Y.Z.Y., Ö.T., H.E., Ö.B.E.; Analysis and/or Interpretation - Y.Z.Y., H.M.Y., H.A.Ö.; Literature Search - U.A., Ö.T.; Writing - Y.Z.Y., U.A.

Conflict of Interest: The authors have no conflict of interest to declare.

Financial Disclosure: This study was supported by the Scientific Research Projects Coordination Unit of İstanbul University (project number: 25617).

\section{REFERENCES}

1. American Cancer Society. Cancer facts and figures. 2007. American Cancer Society; 2007. Available from: http://www.cancer.org/docroot/ STT/stt_0_2007.asp?sitearea=STT\&level=1

2. Lin HW, Bhattacharyya N. Staging and survival analysis for nonsquamous cell carcinomas of the larynx. Laryngoscope 2008; 118: 1003-13.

3. Chu EA, Kim YJ. Laryngeal cancer: diagnosis and preoperative work-up. Otolaryngol Clin North Am 2008; 41: 673-95, v.

4. Hardisson D. Molecular pathogenesis of head and neck squamous cell carcinoma. Eur Arch Otorhinolaryngol 2003; 260: 502-8.

5. Lane EB, Alexander CM. Use of keratin antibodies in tumor diagnosis. Semin Cancer Biol 1990; 1: 165-79.

6. Kramer G, Erdal H, Mertens HJ, Nap M, Mauermann J, Steiner G, et al. Differentiation between cell death modes using measurements of different soluble forms of extracellular cytokeratin 18. Cancer Res 2004; 64: 1751-6.

7. Fuchs E, Weber K. Intermediate filaments: structure, dynamics, function, and disease. Annu Rev Biochem 1994; 63: 345-82.

8. Leers MP, Kölgen W, Björklund V, Bergman T, Tribbick G, Persson B, et al. Immunocytochemical detection and mapping of a cytokeratin 18 neoepitope exposed during early apoptosis. J Pathol 1999; 187: 567-72.

9. Steele N, Plumb JA, Vidal L, Tjornelund J, Knoblauch P, Rasmussen A, et al. A phase I pharmacokinetic and pharmacodynamics study of the histone deacetylase inhibitor belinostat in patients with advanced solid tumors. Clin Cancer Res 2008; 14: 804-10.

10. Ulukaya E, Yılmaztepe A, Akgöz S, Linder S, Karadağ M. The levels of caspase-cleaved cytokeratin 18 are elevated in serum from patients with lung cancer and helpful predict the survival. Lung Cancer 2007; 56: 399404.

11. Hou JM, Greystoke A, Lancashire L, Cummings J, Ward T, Board R, et al. Evaluation of circulating tumor cells and serological cell death biomarkers in small cell lung cancer patients undergoing chemotherapy. Am J Pathol 2009; 175: 808-16.

12. Olofsson MH, Ueno T, Pan Y, Xu R, Cai F, van der Kuip H, et al. Cytokeratin 18 is a useful serum biomarker for early determination of response of breast carcinomas to chemotherapy. Clin Cancer Res 2007; 13: 3198-206.

13. Ozturk B, Coşkun U, Sancak B, Yaman E, Buyukberber S, Benekli M. Elevate serum levels M30 and M65 in patients with locally advanced head and neck tumors. Int Immunopharmacol 2009; 9: 645-8.

14. Ausch C, Buxhofer-Ausch V, Olszewski U, Hinterberger W, Ogris E, Schiessel R, et al. Caspase-cleaved cytokeratin 18 fragment (M30) as a marker of postoperative residual tumor load in colon cancer patients. Eur J Surg Oncol 2009; 35: 1164-8.

15. Koelink PJ, Lamers CB, Hommes DW, Verspaget HB. Circulating cell death products predict clinical outcome colorectal cancer patients. BMC Cancer 2009; 9: 88.

16. de Haas EJ, di Petro A, Simpson KL, Meijer C, Suurmeijer AJ, Lancashire LJ, et al. Clinical evaluation of M30 and M65 ELISA cell death assay as circulating biomarkers in a drug sensitive tumor, testicular cancer. Neoplasia 2008; 10: 1041-8.

17. Hoffman HT, Porter K, Karnell LH, Cooper JS, Weber RS, et al. Laryngeal cancer in the United States: changes in demographics, patterns of care, and survival. Laryngoscope 2006; 116(Suppl 111): 1-13.

18. Cummings J, Hodgkinson C, Odedra R, Sini P, Heaton SP, Mundt KE, et al. Preclinical evaluation of M30 and M65 ELISAs as biomarkers of drug 
induced tumor cell death and antitumor activity. Mol Cancer Ther 2008; 7: 453-65.

19. Greystoke A, Cummings J, Ward T, Simpson K, Renehan A, Butt F, et al. Optimisation of circulating biomarkers of cell death for routine clinical use. Ann Oncol 2008; 19: 990-5.

20. Ueno T, Toi M, Bivén K, Bando H, Ogawa T, Linder S. Measurement of an apoptotic product in the sera of breast cancer patients. Eur J Cancer 2003; 39: 769-74.

21. Dive C, Smith RA, Garner E, Ward T, George-Smith SS, Campbell F, et al. Considerations for the use of plasma cytokeratin 18 as a biomarker in pancreatic cancer. Br J Cancer 2010; 102: 577-82.

22. Yaman E, Coskun U, Sancak B, Buyukberber S, Ozturk B, Benekli M. Serum M30 levels are associated with survival in advanced gastric carcinoma patients. Int Immunopharmacol 2010; 10: 719-22.

23. Bilici A, Ustaalioglu BB, Ercan S, Orcun A, Seker M, Salepci T, et al. Is there any impact of plasma M30 and M65 levels on progression-free survival of patients with advanced gastric cancer? Cancer Chemother Pharmacol 2011; 68: 309-16.

24. Wu YX, Wang JH, Wang H, Yang XY. Study on expression of Ki-67, early apoptotic protein $\mathrm{M} 30$ in endometrial carcinoma, their correlation with prognosis Zhonghua Bing Li Xue Za Zhi 2003; 32: 314-8. (Chinese).

25. Markou K, Goudakos J, Triaridis S, Konstantinidis J, Vital V, Nikolaou A. The role of tumor size and patient's age as prognostic factors in laryngeal cancer. Hippokratia 2011; 15: 75-80.

26. Gonzalez-Marquez R, Rodrigo JP, Suarez Nieto C. Prognostic significance of postoperative wound infections after total laryngectomy. Head Neck 2012; 34: 1023-7.

27. Jose J, Coatesworth AP, Johnston C, MacLennan K. Cervical node metastases in squamous cell carcinoma of the upper aerodigestive tract: the significance of extracapsular spread and soft tissue deposits. Head Neck 2003; 25: 451-6. 